Portland State University

PDXScholar

12-10-1992

\title{
Solidification and Morphology of Submarine Lavas: A Dependence on Extrusion Rate
}

\author{
Ross W. Griffiths \\ Australia National University \\ Jonathan H. Fink \\ Portland State University, jon.fink@pdx.edu
}

Follow this and additional works at: https://pdxscholar.library.pdx.edu/geology_fac

Part of the Geology Commons, and the Volcanology Commons

Let us know how access to this document benefits you.

\section{Citation Details}

Griffiths, R. W., \& Fink, J. H. (1992). Solidification and morphology of submarine lavas: A dependence on extrusion rate. Journal of Geophysical Research: Solid Earth (1978-2012), 97(B13), 19729-19737.

This Article is brought to you for free and open access. It has been accepted for inclusion in Geology Faculty Publications and Presentations by an authorized administrator of PDXScholar. Please contact us if we can make this document more accessible: pdxscholar@pdx.edu. 


\title{
Solidification and Morphology of Submarine Lavas: A Dependence on Extrusion Rate
}

\author{
Ross W. GRIFFTrHS \\ Research School of Earth Sciences, Australian National University, Canberra
}

Jonathan H. FinK

Geology Department, Arizona State University, Tempe

\begin{abstract}
The results of recent laboratory experiments with wax extruded beneath relatively cold water may be extrapolated to predict the surface morphology of submarine lavas as a function of the extrusion rate and melt viscosity. The experiments with solidifying wax indicated that the surface morphology was controlled by a single parameter, the ratio of the time taken for the surface to solidify, and a time scale for lateral flow. For submarine basalts a solution of the cooling problem (which is dominated by conduction in the lava but convective heat transfer in the water) and estimates of lava viscosities place this parameter within the empirically determined "pillowing" regime over a wide range of extrusion rates. This result is consistent with the observation that pillow basalts are the most common products of submarine eruptions. Smoother surfaces corresponding to the various types of submarine sheet flows are predicted for sufficiently rapid extrusions of basaltic magma. Still higher eruption rates in regions of low topographic relief may produce submarine lava lakes. Minimum emplacement times can be calculated for submarine volcanic constructs of a single lava flow type.
\end{abstract}

\section{INTRODUCTION}

Submarine basalt flows are the most common volcanic rocks on earth. However, because the eruption of submarine lavas has never been directly observed, our ability to infer emplacement conditions from their morphology is quite limited. Despite recent concerted efforts to catch deep-sea eruptions in action [e.g., Chadwick et al., 1991; Haymon et al., 1991], the likelihood of being able to make accurate measurements with presently available technology is small. This situation contrasts with that for subaerial flows, whose morphology has been related quantitatively to both lava rheology and effusion rate in several studies [e.g., Hulme, 1974; Fink and Fletcher, 1978; Borgia et al., 1983; Baloga and Pieri, 1986; Rowland and Walker, 1990]. One way to overcome this limitation to our understanding is to use theoretical and laboratory models to relate lava morphology to effusion rate and rheology. This is the approach of this paper.

When lava is extruded onto the Earth's surface or the seafloor, it spreads laterally under the influence of gravity. It also begins to solidify as a result of radiative or convective heat loss from its surface. By observation we know that a thin layer at the surface of the lava can become a solid crust within minutes in the case of subaerial eruptions or within a few seconds when the lava is under water. The time for formation of the first solid is determined by the eruption temperature and rate of heat loss from the surface, and these same parameters determine the subsequent rate of thickening of the solid crust. The properties of the crust, in turn, control its deformation in response to stresses applied by the motion of the underlying melt [e.g., Fink and Fletcher, 1978]. Under some conditions (namely rapid solidification, small extrusion rates, or high melt viscosities) the crust can also exercise some degree of control over the speed of advance of the flow front [R. W. Griffiths and J. H. Fink, Effects of

Copyright 1992 by the American Geophysical Union.

Paper number 92JB01594.

0148-0227/92/92JB-01594\$05.00 solidifying crust on the advance of lava flows and domes, submitted to Journal of Fluid Mechanics, 1992]. Thus the surface cooling and development of the solid crust is a critical process in determining the surface morphology of lavas and, in some cases, may lead to crustal control of the flow's advance.

In a series of laboratory experiments with polyethylene glycol wax extruded onto the base of a tank filled with cold water, Fink and Griffiths [1990,1992] showed that formation of solid crust led to a number of types of surface morphology analogous to those seen on lava flows (Figure 1). These included levees around flow margins, surface folds similar in appearance to those found on ropy basalts, striated surfaces separating large smooth plates along rifting zones, and small bulbous structures similar to pillow basalts (Figure 2). Fink and Griffiths also found that the type of surface morphology dominant in each experiment depended in a systematic manner on the rate of extrusion and the rate of formation of crust: the most rapid cooling and solidification led to "pillow" morphology, whereas "rifting," "folding," and "levees" occurred for progressively slower solidification rates or more rapid extrusion rates. At the lowest cooling rates, no crust at all formed within the duration of an experiment.

A theoretical prediction of the kind of surface morphology to be expected under prescribed laboratory or field conditions is currently beyond our capabilities; it would require complete solutions for the coupled temperature and flow fields taking into account temperature-dependent rheology, solidification, and the mechanics of the crust. Various attempts have been made to predict aspects of the overall spreading of lava flows [Walker, 1973; Malin, 1980; Huppert et al., 1982; Blake, 1990], some considering only the thermal problem in which cooling and solidification throughout much of the depth of the lava column is assumed to bring the flow to a halt [Pinkerton, 1987; Crisp and Baloga, 1990]. However, these papers have not addressed the dynamical effects of the crust on the overall flow nor the relationship between deformation of the crust and the underlying flow.

In conjunction with their laboratory experiments, Fink and Griffiths [1990] employed an alternative approach. On the basis of a dimen- 


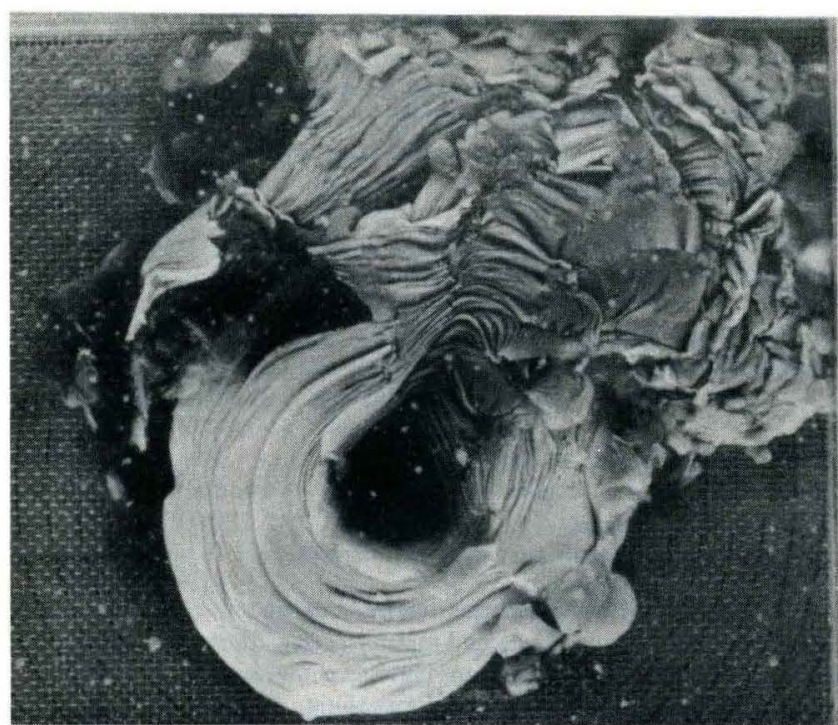

Fig. 1a. Transverse folding on flow from a point source (width of tank is 30 $\mathrm{cm})$.

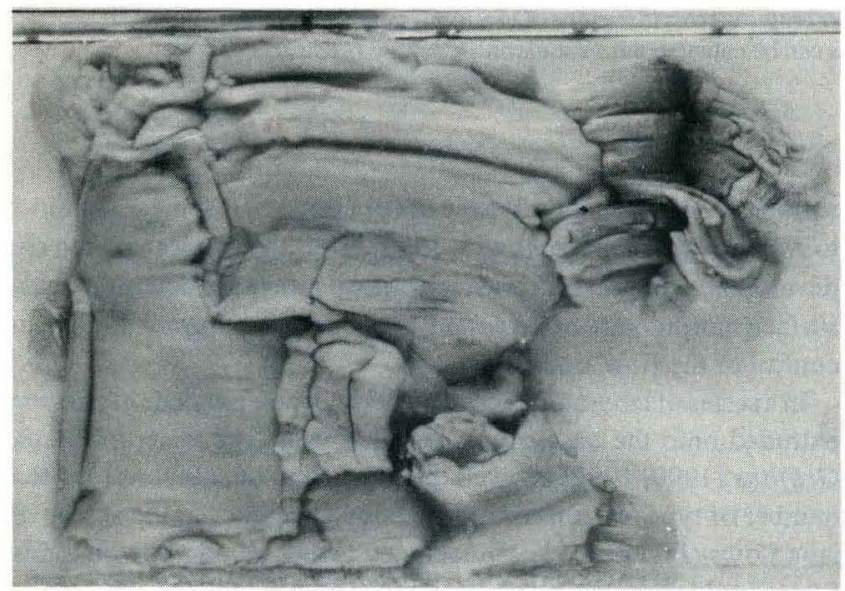

Fig. 1b. "Rifting" or plate-like spreading on an extrusion from a line source whose position is indicated by arrows (tank is $20 \mathrm{~cm}$ from top to bottom).

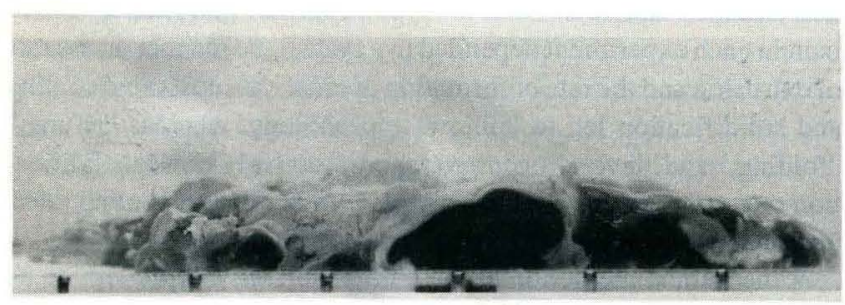

Fig. $1 c$. Side view of spreading from a line source through "pillow" formation (4-cm-thick flow moved toward the camera).

Fig. 1. Photographs of three morphologic regimes in spreading of polyethylene glycol wax under cold water, from the experiments of Fink and Griffiths [1990, 1992].

sional analysis and an assumption of dynamic similarity, they argued that the surface morphology depends primarily on the rate of formation of crust relative to the rate of lateral flow. The behavior can be characterized for each experiment by a single dimensionless parameter, $\Psi$, which they defined as the ratio of the time taken for the surface of the wax to solidify and a time scale for horizontal advection, the latter being a measurement of the time required for an element of extruded wax to travel a distance equal to the depth the flow would have in the absence of solid crust. In the experiments the flow of wax without crust would have been governed by a balance between gravity and viscous stresses. Equivalently, $\Psi$ is the lateral distance from the vent, measured in flow depths, at which solid crust is predicted to appear. Evaluation of this parameter for each wax experiment using a theoretical prediction for the surface cooling, along with the observations of morphology, enabled empirical values of $\Psi$ to be found at the various morphological transitions: when $\Psi>50$, the wax flow reached the walls of the box without crust appearing; at $25<\Psi<50$, solid formed near the flow front and created levees which had to be broken or overridden before the flow could advance; at $10<\Psi<25$ there were cross-stream-oriented folds similar to those on ropy pahoehoe flows; at $3<\Psi<10$ the wax crust developed plates and rift-like fractures, with molten wax exposed along the rifts ultimately freezing and adding to the rigid surface plates that were moving apart; and at $\Psi<3$, crust developed rapidly at the vent and spreading proceeded through large numbers of bulbous outgrowths, or "pillows."

The transitions between dominant morphological types occurred at approximately the same values of $\Psi$ for both radial spreading from a small hole [Fink and Griffiths, 1990] and two-directional spreading from a narrow slit [Fink and Griffiths, 1992] (with spreading rate appropriately scaled for each case). In most respects the morphology was also independent of the roughness and slope of the base, although for a long narrow slit (a line source) the "pillow" regime was observed only with a rough base. With a smooth base, "pillows"were replaced in linear (two-directional) spreading by an extension of the "rifting" regime, presumably because the crust did not grip the smooth base near the flow front and the two large plates could slide away on each side of the line source without decelerating. A gently sloping base (up to six degrees) gave a preferred direction of flow, but the dominant type of surface morphology was otherwise little affected. Thus the laboratory experiments showed a reasonably robust sequence of transitions between surface morphologies, transitions which are described by values of a single parameter relating cooling rate to spreading rate. The dependence of morphology on the parameter $\Psi$ alone (at least for a given material) shows that the surface morphology, and the kind of behavior occurring near the flow front, can be described in terms of the source conditions, extrusion rate, and surface heat flux, with some influence of basal topography.

The laboratory observations of surface morphology provide a potentially powerful tool for interpretation of the emplacement conditions for lava flows. The experiments have been carried out with convective cooling of wax beneath cold water, and the results should be of direct relevance to submarine lava eruptions. In this paper we evaluate the parameter $\Psi$ and make tentative predictions of flow morphology for submarine basaltic lavas. These predictions are functions of the volume flux, eruption temperature, and lava viscosity at the vent. However, if we consider only mid-ocean ridge basalts, the range of vent temperatures and viscosities is likely to be quite limited, and the extrusion rate is left as the main determinant of flow morphology. This opens the possibility that observed morphology may be used to place constraints on variations of extrusion rate along a ridge.

\section{SPREAdING OF Viscous LaVA}

The depth and lateral velocity of lava near a vent, with or without cooling, are determined by the source volume flux Q, source geometry, lava rheology, gravitational force, and base topography. Cooling as a result of heat loss from the surface or base of the lava influences the spreading by altering the rheology of parts of the flow. If there is no vertical advective transport of heat within the lava (i.e., 


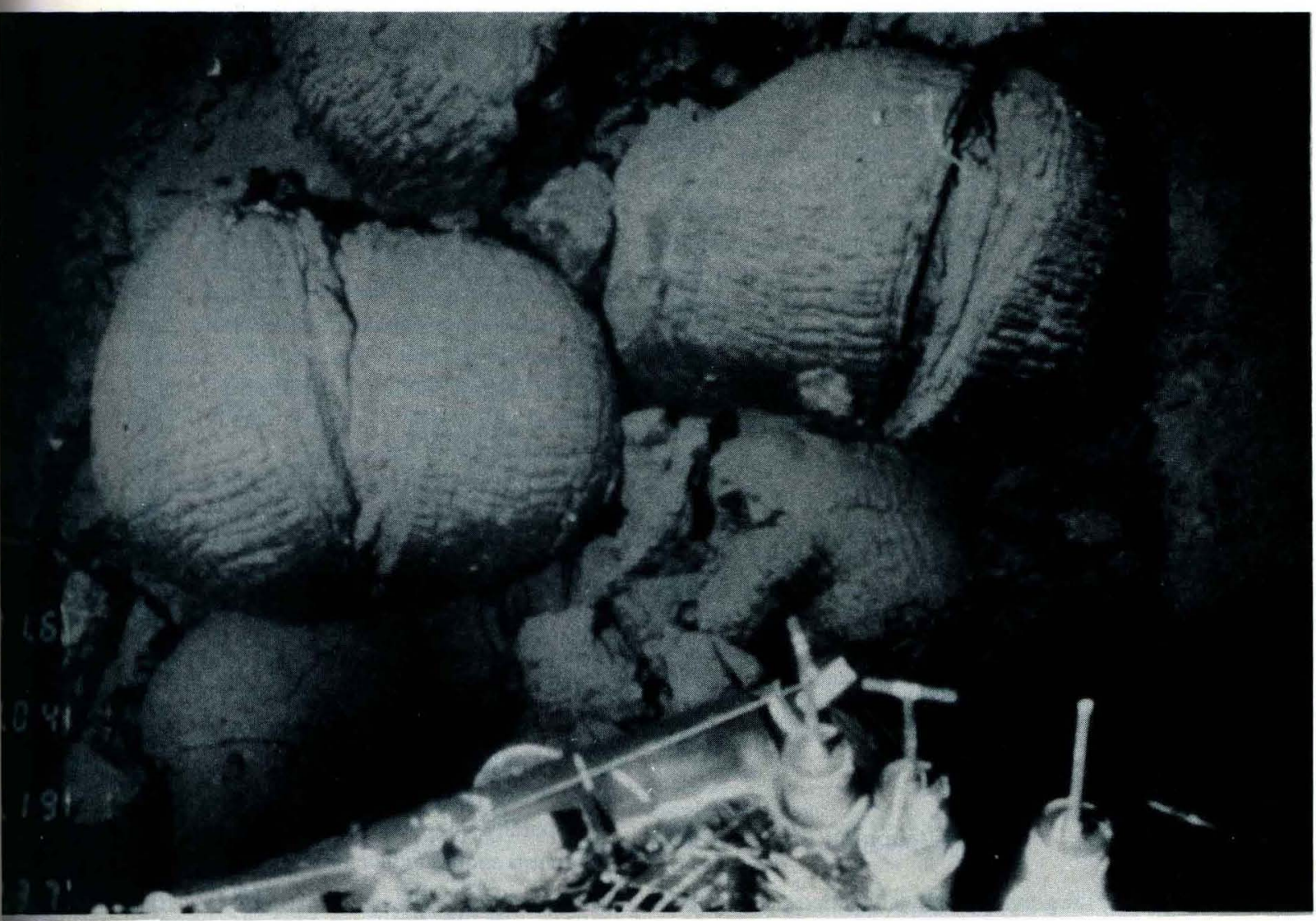

Fig. 2a. ALVIN view of basalt pillows with spreading cracks (individual pillows approximately $1 \mathrm{~m}$ across) from the East Pacific Rise. Photo courtesy of Robert Embley, NOAA.

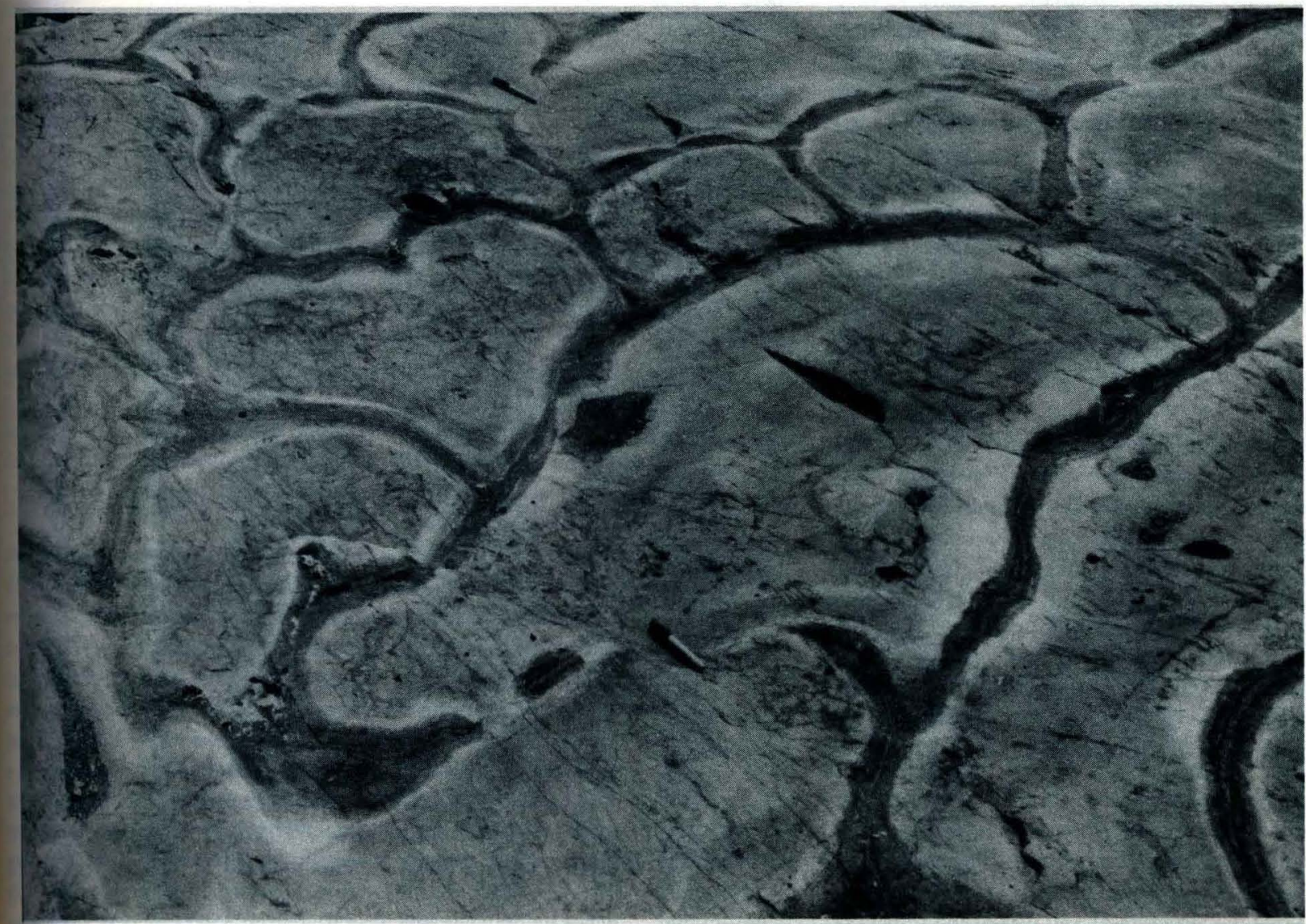

Fig. $2 b$. Archaean pillows from southern Ontario showing dark glassy rinds. Pen near bottom of largest pillow for scale. Photo courtesy of Stephen J. Reynolds, Arizona State University. 
no thermal convection or shear-generated turbulence), cooling is confined to thin conductive boundary layers: a thin solid crust develops. In this paper we consider only laminar (or near-laminar) flows: those having viscosities small enough and velocities large enough for a Reynolds number to be greater than about 100 are generally unstable or turbulent, and conduction is not the sole mechanism for heat transport to their surfaces. Because solidification commences much more slowly at the base than at the exposed surface of a lava, we also neglect any effects of basal cooling on the overall flow or on development of the surface crust and its morphology. Thermal convection in the lava cannot commence within the extremely short times required for a solid surface skin to form in contact with water.

Assuming that the isothermal melt beneath the surface boundary layer can be satisfactorily described by a uniform viscosity, the rate of formation of surface crust can be compared to the rate of spreading that would prevail in the absence of cooling. For a flow with Newtonian rheology and a very small Reynolds number extruded onto a horizontal plane, scales for the depth $\mathrm{H}$ and velocity $\mathrm{U}$ of the flow [Fink and Griffiths, 1990] are, for radial spreading from a point source,

$$
\mathrm{H} \sim(\rho \vee \mathrm{Q} / \mathrm{g} \Delta \rho)^{1 / 4}, \quad \mathrm{U} \sim(\mathrm{g} \Delta \rho \mathrm{Q} / \rho v)^{1 / 2}
$$

and, for a line (slit) source,

$$
\mathrm{H} \sim(\rho v q / g \Delta \rho)^{1 / 3}, \quad \mathrm{U} \sim\left(\mathrm{g} \Delta \rho q^{2} / \rho v\right)^{1 / 3} .
$$

The motion is driven by the gravitational acceleration $\mathrm{g}$ acting on the density difference $\Delta \rho=\rho-\rho_{a}$, where $\rho$ is the density of the lava and $\rho_{\mathrm{a}}$ is density of the environment. Flow is retarded by stresses associated with the kinematic viscosity $v(v=\eta / \rho$, where $\eta$ is the dynamic viscosity). In ( $1 a), \mathrm{Q}$ is the volume flux from the vent, whereas in $(1 b)$, q is the volume flux per unit length of the line source. Constants of proportionality are not shown here but will be of order one; their precise values are not needed, as the dimensionless parameter which we will form using the above scales must in any case be evaluated empirically at the various morphological transitions, using laboratory analog experiments or field data.

The time for advection of lava through a distance equal to one depth scale, $t_{a}=H / U$, is found from (1). The ratio of solidification and advective time scales $\Psi=t_{s} / t_{a}$ (which can be thought of as the inverse of a "solidification Peclet number," instead of the usual "heat flow Peclet number") then becomes

$$
\text { Radial spreading } \quad \Psi=(\mathrm{g} \Delta \rho / \rho v)^{3 / 4} \mathrm{Q}^{1 / 4} \mathrm{t}_{\mathrm{s}}
$$

Line source

$$
\Psi=(\mathrm{g} \Delta \rho / \rho v)^{2 / 3} \mathrm{q}^{1 / 3} \mathrm{t}_{\mathrm{s}} .
$$

In order to estimate $\Psi$ for a given flow it is necessary to evaluate the time $t_{s}$ required for the surface of the lava to cool from the vent temperature to the solidification temperature. The time $t_{\mathrm{s}}$ is used here as the primary indicator of the development of crust during the early stages of solidification of flow from those positions where new melt is exposed to the environment. At much greater times when the lava surface is farther from the vent and its temperature has approached the ambient temperature, the crust thickness becomes insensitive to the surface solidification time and is instead controlled largely by the thickness of the thermal boundary layer. However, we proceed under the assumption that crust morphology, such as pillows and transverse folds, is determined by the early stages of development of the crust and that the structure of any part of the flow is set long before that portion of the surface has time to cool to the ambient temperature.

\section{Surface CoOling and Solidification}

\section{Surface Fluxes}

An analysis of the cooling of lava, assuming that vertical heat transfer within the lava is by conduction and that the surface flux is determined by turbulent natural convection in the environment, is summarized by Fink and Griffiths [1990]. Convective transport is expected to be the dominant mechanism for heat loss from submarine eruptions. However, there is also a small radiative transfer, and for completeness we include estimates of this flux. Thus the surface flux $\mathrm{F}$ is given by the sum of the convective flux $\mathrm{F}_{\mathrm{c}}$ and the radiative flux $\mathrm{F}_{\mathrm{r}}$. The magma motion is assumed to be laminar (at least near its surface), and we show later that there is no need to consider therma convection within the magma.

Consider an element of lava extruded at a time $t=0$ and temperature $T_{1}$ under a deep layer of seawater at temperature $T_{a}$. At extremely small times after any given element of melt comes into contact with the seawater, a conductive thermal boundary layer builds up in the water adjacent to the lava surface until it becomes unstable and is swept away by convection. Using a boundary layer analysis (and assuming single-phase flow) it is straightforward to show that this boundary layer timescale is of order $10^{-2} \mathrm{~s}$ (taking seawater properties in Table 1). This is also the timescale for the boundary layer to reform. Boundary layer intermittence results in fluctuations of the surface heat flux. However, at times much greater than $10^{-2} \mathrm{~s}$, only a temporally smoothed flux is required. Increased surface slope and roughness should reduce both the boundary layer timescale and the magnitude of the fluctuations in heat flux.

The convective flux $\mathrm{F}_{\mathrm{c}}$ established for convection at large Rayleigh numbers in water, with small temperature differences and no boiling, is given by

$$
F_{c}=J\left(T_{c}-T_{a}\right)^{4 / 3}, \quad J=\rho_{a} c_{a} \gamma\left(g \alpha_{a} \kappa_{a}{ }^{2} / v_{a}\right)^{1 / 3},
$$

where $T_{c}(t)$ is the lava temperature at the contact surface, $\alpha_{a}, \kappa_{a}, v_{a}$ $\rho_{\mathrm{a}}$, and $c_{\mathrm{a}}$ are the thermal expansion coefficient, diffusivity, kinematic viscosity, density, and specific heat (at constant pressure) 0 the convecting fluid, and $\gamma$ is a constant whose value is close to 0.1 [Turner, 1973; Huppert and Sparks, 1988]. The molecular properties of water are almost constant in all existing tests of (3). However, at high temperatures, seawater exhibits a strong dependence of thermal expansion coefficient on temperature [Bischoff and Rosenbauer 1985]: for the seawater at mid-ocean ridges (3.2\% to $3.5 \%$ salinity and $100-300$ bar), $\alpha$ varies from $1.5 \times 10^{-4}$ at the ambient temperature $\left(0^{\circ}-10^{\circ} \mathrm{C}\right)$ [Sverdrup, 1945] to $1.0 \times 10^{-2}$ at $350^{\circ}-420^{\circ}$ (depending on pressure). At conditions close to the critical point of seawater (approximately $400^{\circ} \mathrm{C}, 300 \mathrm{bar}$ ) the expansion coefficient becomes even larger. It is therefore important to make allowance for a nonlinear density-temperature relation.

Convective heat transfer from submarine lavas is controlled by the dynamics of a thin unstable boundary layer in the water (as well a conduction through a thin boundary layer in the lava). As far as we are aware, the effects of strongly nonlinear density-temperatur relations on this form of convection have not been parameterized However, we argue that the convective heat flux depends on the ne buoyancy in the boundary layer and therefore on an "effective" average value for $\alpha_{a}$, which might be defined such that $\alpha_{a}\left(T_{c}-T_{a}\right)$ $\delta^{-1} \int_{0}^{\delta} \alpha(\mathrm{T})\left(\mathrm{T}-\mathrm{T}_{\mathrm{a}}\right) \mathrm{dz}$, where $\mathrm{z}=0$ at the contact surface and $\delta$ is th thickness of the unstable boundary layer. The best justifiable proximation for the effective $\alpha_{\mathrm{a}}$ is simply $\alpha_{\mathrm{a}} \approx \alpha\left(\mathrm{T}^{*}\right)$, wh $\mathrm{T}^{*}=\left(\mathrm{T}_{\mathrm{c}}+\mathrm{T}_{\mathrm{a}}\right) / 2$. For the early stages of cooling considered in this paper we will see that $\mathrm{T}^{*}$ varies from $350^{\circ} \mathrm{C}$ to $550^{\circ} \mathrm{C}$, a range ove which the minimum expansion coefficient is $\alpha_{\mathrm{a}} \approx 3 \times 10^{-3}$, and 
TABLE 1. Values of Parameters for Seawater and Basaltic Lavas Used in the Computation of Cooling and Time Scales for Lateral Flow of the Lava

$\begin{array}{llll}\text { Parameter Description } & \text { Value }\end{array}$

Seawater at Depths $1000-4000 \mathrm{~m}$

$\begin{array}{llll}\eta_{\mathrm{a}}, \mathrm{Pa} \mathrm{s} & \text { dynamic viscosity } & 1 \times 10^{-3} & \text { [Dietrich et al., 1980] } \\ \nu_{\mathrm{a}}, \mathrm{m}^{2} \mathrm{~s}^{-1}, & \text { kinematic viscosity } & 1 \times 10^{-6} & \\ \mathrm{c}_{\mathrm{a}}, \mathrm{J} \mathrm{kg}^{-1} \mathrm{~K}^{-1} & \text { specific heat } & 4.0 \times 10^{3} & \text { [Fofonoff, 1962] } \\ \kappa_{\mathrm{a}}, \mathrm{m}^{2} \mathrm{~s}^{-1} & \text { thermal diffusivity } & 1 \times 10^{-7} & \text { [Weast et al., 1989] } \\ \rho_{\mathrm{a}}, \mathrm{kg} \mathrm{m}^{-3} & \text { density } & 1.00 \times 10^{3} & \text { [Fofonoff, 1962] } \\ \alpha \text { at ambient } \mathrm{T}, \mathrm{K}^{-1} & \text { thermal expansion } & 1.5 \times 10^{-4} & \text { [Sverdrup, 1945] } \\ \alpha_{\mathrm{a}} \text { at } \sim 400^{\circ} \mathrm{C}, \mathrm{K}^{-1} & & \sim 10^{-2} & \text { [Bischoff and Rosenbauer, 1985] } \\ \mathrm{T}_{\mathrm{a}}, \mathrm{K} & \text { temperature } & 280 & \text { [Dietrich } \text { et al., 1980] }\end{array}$

Balsaltic Lava

$\eta, \mathrm{Pa} \mathrm{s}^{2}$
$\mathrm{v}, \mathrm{m}^{2} \mathrm{~s}^{-1}$
$\mathrm{c}, \mathrm{J} \mathrm{kg}^{-1} \mathrm{~K}^{-1}$
$\mathrm{~K}, \mathrm{~m}^{2} \mathrm{~s}^{-1}$
$\rho, \mathrm{kg} \mathrm{m}^{-3}$
$\mathrm{~T}_{1}, \mathrm{~K}$
$\mathrm{~T}_{\mathrm{s}}, \mathrm{K}$
$\varepsilon$

$\varepsilon$
$10^{2}-10^{4}$

0.044

$1.2 \times 10^{3}$

$5 \times 10^{-7}$

$2.6 \times 10^{3}$

$\sim 1423$

1003

emissivity
[Hall, 1987]

[Turcotte and Schubert, 1982]

[Williams and McBirney, 1979]

[Hall, 1987]

(estimate from Macdonald [1972])

[Ryan and Sammis, 1981]

value assumed

The solidification temperature $\mathrm{T}_{\mathrm{s}}$ is assumed to be the glass transition.

maximum is of order $10^{-1}$, for which a more representative value is $a_{a}=0.01$ [Bischoff and Rosenbauer, 1985].

An estimate of the radiative flux $\mathrm{F}_{\mathrm{r}}$ which will be sufficient for our purposes is

$$
\mathrm{F}_{\mathrm{r}}=\varepsilon \sigma\left(\mathrm{T}_{\mathrm{c}}{ }^{4}-\mathrm{T}_{\mathrm{a}}^{4}\right),
$$

where $\sigma$ is the Boltzmann constant and $\varepsilon$ is the emissivity of the surface. Stefan's law (4) may tend to overestimate the radiative flux, where some fraction of the radiation at long infrared wavelengths will be absorbed within the thin conductive thermal boundary layer in the water and therefore left to be carried away as a part of the convective flux $\mathrm{F}_{\mathrm{c}}$. However, most of the radiation penetrates beyond the boundary layer (a thickness of $\sim 3 \times 10^{-2} \mathrm{~mm}$ ) and adds to the total flux.

Griffiths and Fink [1992] present explicit values for the surface fluxes calculated from (3) and (4) and compare them with the fluxes from lava surfaces in subaerial environments. They range up to 5000 $\mathrm{kW} \mathrm{m}^{-2}$.

\section{The Contact Temperature}

The idealized cooling problem to be solved is that in which melt of uniform temperature $T_{1}$ is suddenly brought into contact with overlying water at temperature $\mathrm{T}_{\mathrm{a}}$. Conduction in the lava is matched to the total surface flux, which in turn depends on the surface temperature and ambient conditions. No allowance for latent heat is required over the small time scales of interest, since the rapid quenching by water leads to vitrification of the lava surface with no crystallization (see below). A solution for the contact temperature $\mathrm{T}_{c}(\mathrm{t})$, assuming only convective transfer from the surface, was given in dimensionless form by Fink and Griffiths [1990]. Here we calculate explicitly both the contact temperature and thickness of solidified crust under conditions appropriate for submarine extrusions of basalt. Given this limited range of conditions, the results are more accessible when expressed in dimensional form.
The problem of finding the temperature in the lava can be reduced, using standard techniques, to solution of an integral equation [Carslaw and Jaeger, 1959, p. 76]. The equation can be transformed into

$$
\mathrm{T}(\mathrm{z}, \mathrm{t})-\mathrm{T}_{1}=\frac{-1}{\rho \mathrm{c}(\kappa \pi)^{1 / 2}} \int_{0}^{\mathrm{t}} \mathrm{F}(\lambda) \mathrm{e}^{-\mathrm{z}^{2} / 4 \kappa(\mathrm{t}-\lambda)} \frac{\mathrm{d} \lambda}{\sqrt{\mathrm{t}-\lambda}},
$$

where $\mathbf{z}$ is the distance from the contact surface, and $\lambda$ is a dummy variable. In our case the time-dependent surface flux is

$$
\mathrm{F}(\mathrm{t})=\varepsilon \sigma\left[\mathrm{T}_{\mathrm{c}}(\mathrm{t})^{4}-\mathrm{T}_{\mathrm{a}}{ }^{4}\right]+\mathrm{J}\left[\mathrm{T}_{\mathrm{c}}(\mathrm{t})-\mathrm{T}_{\mathrm{a}}\right]^{4 / 3},
$$

where $\rho, c$, and $\kappa$ are the density, specific heat, and thermal diffusivity of the lava (values are shown in Table 1), and $\mathrm{T}_{\mathrm{c}}=\mathrm{T}(\mathrm{z}=0)$. The depth of isotherms can be traced as functions of time. The contact temperature is found by solving with $\mathrm{z}=0$.

The computed depths of several isotherms are shown in Figure s for the case of a basalt extruded at $1423 \mathrm{~K}\left(1150^{\circ} \mathrm{C}\right)$ into seawater at $280 \mathrm{~K}\left(7^{\circ} \mathrm{C}\right)$, assuming $\alpha_{a}=0.01$. The isotherm at $1373 \mathrm{~K}\left(1100^{\circ} \mathrm{C}\right)$ is chosen as an estimate of the solidus temperature for basalts; $1003 \pm 15$ $\mathrm{K}\left(730^{\circ} \mathrm{C}\right)$ is the best available value for the glass transition temperature [Ryan and Sammis, 1981]; and $1200 \mathrm{~K}$ is simply an intermediate temperature. When $1 \mathrm{~s}$ has elapsed, the solidus and glass transition temperature have propagated $2 \mathrm{~mm}$ and $0.5 \mathrm{~mm}$, respectively, into the lava. After this time the depth of these isotherms continues to increase as $t^{1 / 2}$. In Figure 4 we plot the evolution of the contact temperature for the above extrusion. The influence of radiative transport is small, contributing only approximately $5 \mathrm{~K}$ to the surface cooling or decreasing by $4 \%$ the time taken for $\mathrm{T}_{\mathrm{c}}$ to reach the glass transition. The results are not radically different if $\alpha_{a}$ is varied by a factor of 5 .

\section{Solidification Times}

Our model is based on the hypothesis that flow morphology is largely dependent on the relative rates of lateral spreading and crust formation. We have presented evidence [Fink and Griffiths, 1990, 


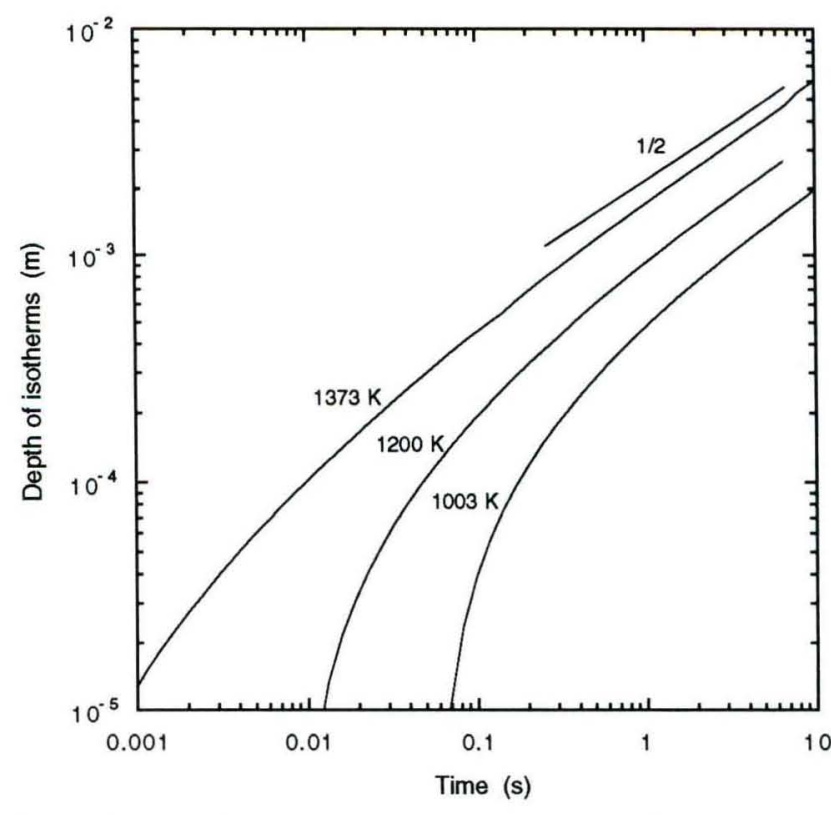

Fig. 3. Numerical solutions for the depth of three isotherms beneath a horizontal surface of lava initially at uniform temperature $\left(T_{1}=1423 \mathrm{~K}\right)$ after it is brought into contact with seawater at $T_{a}=280 \mathrm{~K}$. Values used for physical quantities are given in Table 1 . A slope of $1 / 2$ is shown for comparison.

1992] that an important measure of the rate of crust development is the time taken for the contact surface to begin to solidify. This time can be used to evaluate the dimensionless parameter $\Psi$, but we do not imply that flow morphology is in some way established at the time solid first begins to form in the early stages of an extrusion. Times at which the submarine lava surface passes through its solidus and its glass transition temperature have both been determined, and corresponding solutions for different eruption temperatures are plotted in Figure 5. The time required for cooling to the glass transition varies from $0.14 \mathrm{~s}$ at $\mathrm{T}_{1}=1600 \mathrm{~K}$ to $0.04 \mathrm{~s}$ at $\mathrm{T}_{1}=1300 \mathrm{~K}$. Over this range the surface always cools below the lava solidus in less than $10^{-2} \mathrm{~s}$.

The calculated cooling times are much too small for any crystallization to occur in the thin surface layer after it cools below the

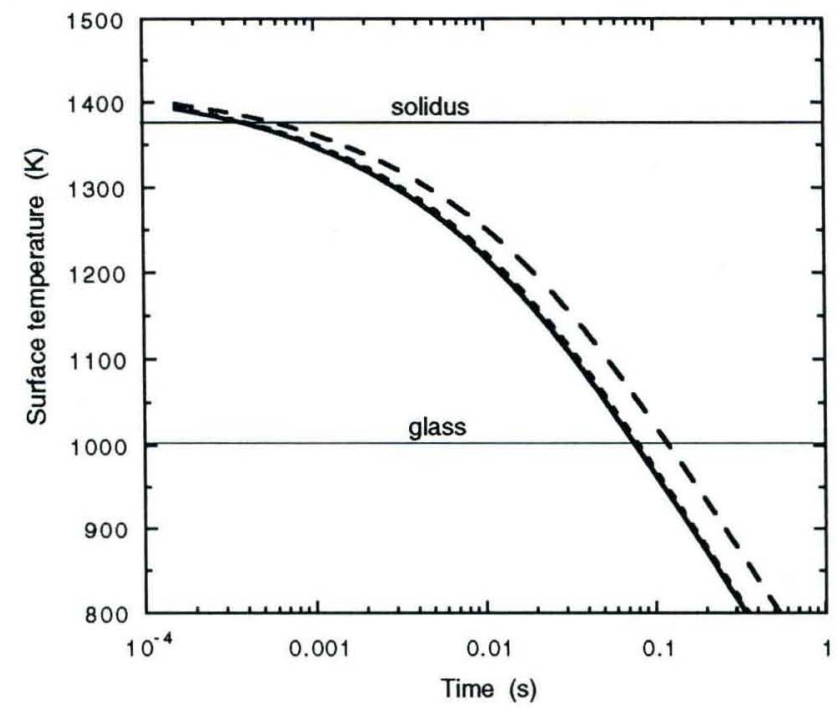

Fig. 4. Solutions for the temperature of the contact surface between lava and seawater for the case $T_{1}=1423 \mathrm{~K}, T_{a}=280 \mathrm{~K}$, and $\alpha_{a}=0.01$ with both radiative and convective transport (solid curve), $\alpha_{\mathrm{a}}=0.01$ and only convective flux (dotted curve), and $\alpha_{a}=0.002$ with both radiation and convection from the lava surface (dashed curve). solidus temperature and before it reaches the glass transition. Work on the crystallization kinetics of igneous rocks and lunar basalts[e.g., Uhlmann et al., 1979; Dowty, 1980; Kirkpatrick, 1981] indicates that homogeneous nucleation and growth of crystals to significant vol. ume fractions requires minimum times of order $10^{3}-10^{4} \mathrm{~s}$ after the melt is cooled from its liquidus. Heterogeneous nucleation due to preexisting crystals may decrease the time to reach large crystal fractions but not by more than an order of magnitude. Thus solidifi. cation near the quenched surface involves only the formation of glass, a prediction that is confirmed by the glassy surfaces found on fresh submarine basalts [e.g., Ballard and Moore, 1977; Chadwickel al., 1991]. Carrying the calculations of isotherm depths to greater times than shown in Figure 3, we find that large volume fractions o crystals are unlikely to form before the lava solidifies to a glass, unti the solidification front has migrated to depths of 50-100 $\mathrm{mm}$ (or a around 1 hour after that part of the surface was exposed to the water) This prediction, too, is consistent with the thickness $(50-60 \mathrm{~mm}$ [Moore and Lockwood, 1978]) of observed glass layers on the outer surface of pillow basalts.

We conclude that the best estimate of the solidification time, ts appropriate for use in extrapolating laboratory observations of sur face morphology to submarine extrusions of basalt is the time take for the lava surface to cool to the glass transition temperature. For a extrusion temperature of $1423 \mathrm{~K}, \mathrm{t}_{\mathrm{s}}=0.07 \mathrm{~s}$. This calculated solidif cation time also appears to be consistent with observations of th visible radiation from submarine lavas. The red glow from a element of lava persists for approximately 1-3 $\mathrm{s}$ after it is exposed to the water at the neck of a new pillow outgrowth [Tepley and Moore 1974]. From independent measurements the last visible red glon from lava corresponds to a temperature of around $900 \mathrm{~K}$ [William and McBirney, 1979]. Although we predict the surface to cool to thi temperature within $0.2 \mathrm{~s}$, the visible radiation is expected to penetrat from the hot interior through a cooler glassy crust for some time. Hence, the two observations and the present cooling model are consistent if the glass is up to $1 \mathrm{~mm}$ thick before it becomes opaque

\section{Predicted Submarine MoRPhology}

Having an estimate for the surface solidification time, $t_{5}$, the parameter $\Psi$ can be evaluated using equations $(2 a)$ and $(2 b)$. Com parison of these values of $\Psi$ with those for the laboratory wax

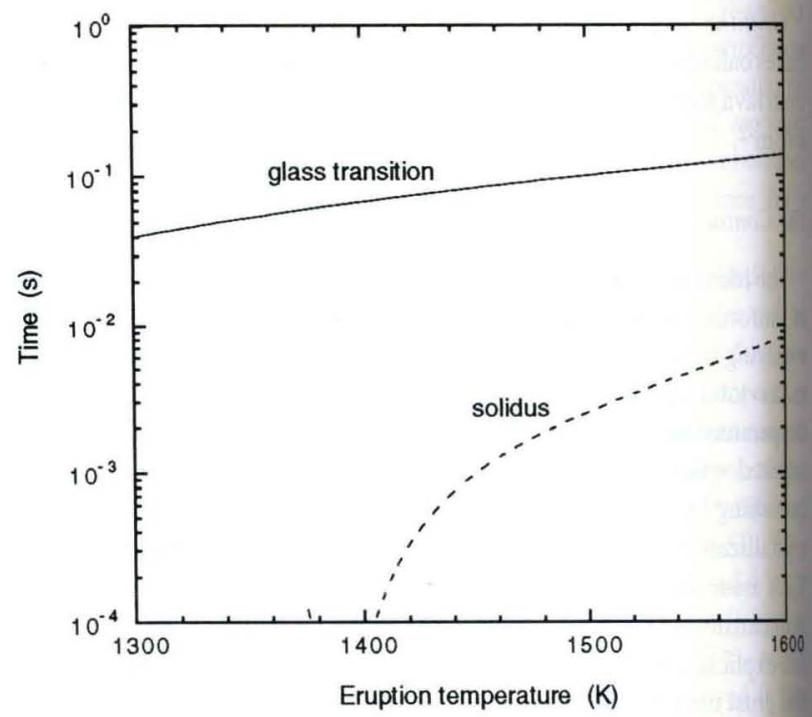

Fig. 5. The time elapsed for the submarine lava surface to cool to the solidus and glass transition temperature, as functions of the extrusion temperatur 
experiments may then help us to understand the surface morphology of the submarine lavas.

In Figure 6 we have plotted the calculated values of $\Psi$ for submarine basalts as a function of the melt viscosity, $\eta$, and the extrusion rate, $\mathrm{Q}$ and $\mathrm{q}$, for both radial spreading from a point source (Figure $6 a$ ) and spreading in two directions from a line source (Figure $6 b)$, respectively. Estimates of the viscosities of basalts fall in the range $10^{2}$ to $10^{4} \mathrm{~Pa} \mathrm{~s}\left(10^{3}-10^{5}\right.$ poises) [Macdonald, 1972; Hall, 1987]. Flow rates for individual eruptions at mid-ocean ridges are not well known but may well be up to $10^{3} \mathrm{~m}^{3} \mathrm{~s}^{-1} \mathrm{~m}^{-1}\left(10^{2} \mathrm{~km}^{3} \mathrm{~d}^{-1} \mathrm{~km}^{-1}\right)$. By way of comparison, the extrusion of basaltic andesite magma in the 1991 eruption of Hekla Volcano in Iceland (a volcanic system attributed to a mantle hotspot at the mid-ocean ridge) ranged from $2000 \mathrm{~m}^{3} \mathrm{~s}^{-1}$ during initial fissure-fed activity to $1-12 \mathrm{~m}^{3} \mathrm{~s}^{-1}$ during the following 2 months when lava issued from a single crater [Gudmundsson et al., 1992]. The 1984 eruption of Mauna Loa (another hotspot volcano) poured out up to $780 \mathrm{~m}^{3} \mathrm{~s}^{-1}$ of tholeiitic basalt [Lipman and Banks, 1987]. Magma flow rates relevant to the formation of surface morphology may often be much smaller than the
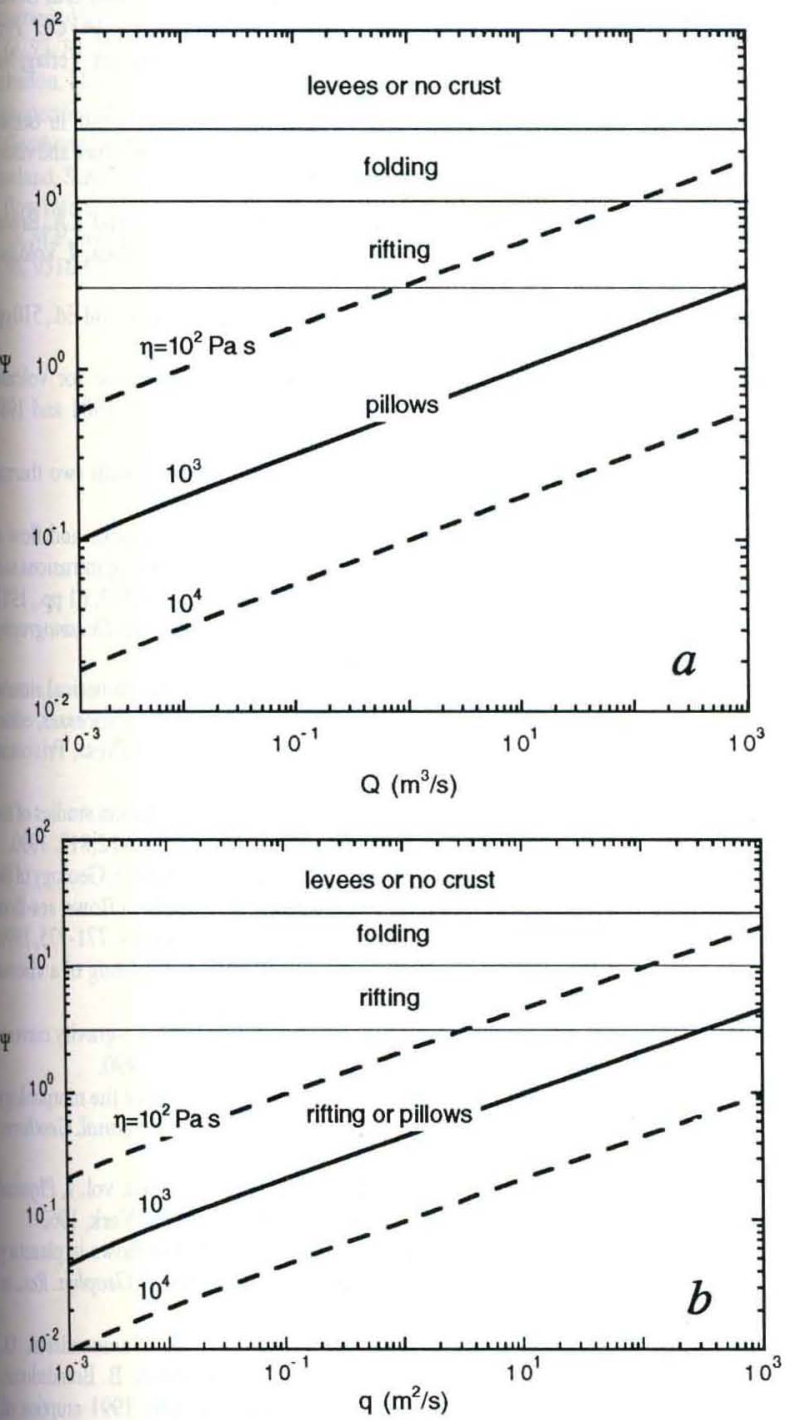

Fig. 6. Values of the dimensionless solidification time $\Psi$ for submarine basaltserupted at $T_{1} \approx 1423 \mathrm{~K}$ as a function of extrusion rate and melt viscosity for $(a)$ radial spreading from a point source and $(b)$ spreading in two directions from a line source. Morphologic regimes indicated by the laboratory experiments of Fink and Griffiths [1990, 1992] are shown. total flux from the vent, since branching of the flow will effectively reduce the local flow rate. Films and videos of submarine portions of Hawaiian basalt flows that erupted subaerially [Tepley and Moore, 1974; Moore, 1975; Sansome, 1990] show that pillow formation and growth is associated with local flow rates of between 0.1 to $2.0 \mathrm{~m}^{3} \mathrm{~s}^{-1}$.

These estimates for viscosity and flow rate imply that $\Psi<3$ is probable for most submarine eruptions (Figure 6). That is, extrapolation of the empirical morphological regimes for the wax analog places submarine lava eruptions largely in the "pillow" regime. This result is consistent with the observation that pillow basalts are common at both ocean ridges and intraplate volcanoes [e.g., Moore, 1975]. If the wax results can be carried over in such a direct manner, we also predict that eruptions with lava viscosities less than $10^{3} \mathrm{~Pa}$ and flow rates greater than $10 \mathrm{~m}^{3} \mathrm{~s}^{-1}$ may form into broad plate-like sheet flows (the "rifting" regime) which would be either smooth or covered with millimeter-scale, flow-parallel striations. Ateven higher flow rates or lower viscosities, transverse folds may develop. Any reduction of flow rate due to branching of these low-temperature basaltic flows will accentuate the tendency to form pillows. Submarine lava lakes, described in detail from sites along the Galapagos Rift [Ballard et al., 1979] and East Pacific Rise [Lonsdale, 1977a; Ballard et al., 1981], and extensive flood basalts on the Hawaiian arch [Holcomb et al., 1988] may represent flows that advance with relatively little crust formation. These would be analogous to the "levee" or "no crust" regimes identified in our experiments and would require extremely high effusion rates (greater than $2000 \mathrm{~m}^{3} \mathrm{~s}^{-1}$ $\mathrm{m}^{-1}$ or $3000 \mathrm{~m}^{3} \mathrm{~s}^{-1}$ for lava with a viscosity of $10^{2} \mathrm{~Pa}$ s extruding from a linear or point source vent, respectively).

If magma issues from a long submarine fissure, the flow rate, q, per unit length of the fissure is smaller than the total volume flux, Q, and Figure $6 b$ indicates a shift to smaller $\Psi$ values, placing submarine basalts still farther into the "pillow" regime than indicated by the point source model. On the other hand, the experiments with line sources revealed no "pillow" regime when a smooth base was used. Thus if the surfaces of previous submarine flows are smooth enough so that new lobes can slide across them, then elongate vents at ridges may initially produce sheet flows at the expense of pillows. As was concluded for point sources, sufficiently rapid submarine eruptions from long fissures could produce flows whose surfaces are smooth, apart from centimeter-scale transverse folds and millimeter-scale striations. The folds may be confined to a region near the flow margins if extrusion from the vent was rapid but of short duration.

Subaerial dike-fed fissure eruptions normally are thermally unstable, constricting to one or a few point-source vents within a few hours [Delaney and Pollard, 1981]. This tendency would be enhanced for eruptions into cold seawater. Thus the experiments in which wax extrudes from a fissure are probably only relevant to the early stages of most submarine eruptions.

The results shown in Figure 6 can help explain distributions of flow types described from a variety of submarine environments [e.g., Lonsdale, 1977a, b; van Andel and Ballard, 1979; Ballard et al., 1979, 1981; Bonatti and Harrison, 1988]. For example, Bonatti and Harrison [1988] measured the areas covered by sheet flows and pillows on maps from many different mid-ocean ridge segments and found a positive correlation between the proportion of sheet flow coverage and the spreading rate of the ridge. They suggested that sheet flow formation is favored in lavas that have higher eruption temperatures and extrusion rates and lower crystallinities and viscosities. Although it seems likely that some of these conditions might be associated with fast spreading ridges, Bonatti and Harrison [1988] could not determine which would most influence flow morphology. In contrast, the dimensionless variable, $\Psi$, allows us to 
calculate the relative importance of these four factors. For example, if we assume that eruption temperature and crystallinity control lava viscosity (v), as described by various experimental studies [e.g., Shaw, 1969; Pinkerton and Stevenson, 1992], then from Fink and Griffiths [1990, equations (3) and (12)] we find that the distance at which surface solidification first occurs (and hence the flow morphology) varies as $\left(Q^{3} / v\right)^{1 / 8}$. Thus volume flow rate should have a stronger influence on morphology than crystallinity or lava viscosity.

Some of the most detailed maps of submarine lava flows yet compiled are from the summit region of Axial Volcano on the Juan de Fuca Ridge [Embley et al., 1990]. These maps distinguish pillows from lobate, ropy, and jumbled sheet flows. Although there are no observations of the latter three types during formation, their appearance suggests that they may correspond to the morphologic sequence seen in our experiments (with jumbled sheet flows equivalent to leveed flows). Thus, if we assume a lava viscosity of $10^{2} \mathrm{~Pa} \mathrm{~s}$, Figure $6 a$ lets us infer that the flow types require the following extrusion rates:

\begin{tabular}{|c|c|c|c|c|}
\hline & & pillows & $<$ & $1 \mathrm{~m}^{3} \mathrm{~s}^{-1}$ \\
\hline $1 \mathrm{~m}^{3} \mathrm{~s}^{-1}$ & $<$ & lobate sheet flows & $<$ & $100 \mathrm{~m}^{3} \mathrm{~s}^{-1}$ \\
\hline $100 \mathrm{~m}^{3} \mathrm{~s}^{-1}$ & $<$ & ropy sheet flows & $<$ & $3000 \mathrm{~m}^{3} \mathrm{~s}^{-1}$ \\
\hline $3000 \mathrm{~m}^{3} \mathrm{~s}^{-1}$ & $<$ & jumbled sheet flows & & \\
\hline
\end{tabular}

These estimates constitute the first attempts to establish the physical conditions needed to form specific types of submarine lava morphology. However, they are based on a direct extrapolation from wax experiments, and their validity for lava, with its vastly different mechanical properties and generally more complex emplacement histories, must be further tested in future studies that include careful examination of lava flow structure from a variety of submarine settings.

Finally, for submarine volcanic constructs made of a single lava flow type, like pillow mounds, our modeling allows us to calculate minimum emplacement times. For example, Figure $6 a$ indicates that a subcircular pillow mound with a volume of $10^{6} \mathrm{~m}^{3}$ and a viscosity of $10^{2} \mathrm{~Pa}$ s could not have formed in less than $10^{6} \mathrm{~s}$, or roughly 12 days (it could take longer if effusion were not continuous). These types of estimates are needed to develop strategies for observing submarine eruptions whose locations are detected by the presence of hydrothermal megaplumes [Embley et al., 1991] or other signs of activity.

\section{ConClusions}

A sequence of morphologic transitions observed on the surface of a wax analog to lava flows can be compared to the structure of submarine lavas by using a simple viscous gravity-driven flow scaling, along with estimates for cooling of the lava surface due to turbulent natural convection in the seawater. The main task involved is a calculation of the time required for the lava surface to solidify after it comes into contact with seawater. A direct application of the laboratory results for morphologic transitions to submarine conditions predicts that basalts are most likely to form into pillows, while lobate, ropy, and jumbled sheet flows and lava lakes form from progressively higher flow rates and/or lower viscosities (crystallinities). Extrusion from a fissure also favors development of pillows unless the substrate is smooth enough to allow the new lava to slide over it, in which case the various types of sheet flow will be favored. In most cases such fissure eruptions will evolve to one or a few isolated subcircular vents quite rapidly. The morphologic similarities between laboratory wax flows and submarine lavas are an encouraging indication that these types of simulations may help answer important questions about the emplacement of lavas on the sea floor.
Acknowledgments. We thank Derek Corrigan and Tony Beasley for construction of equipment and assistance with the experiments and Robert Embley and William Chadwick for helpful discussions about submarine flow morphology. The paper was improved significantly by reviews from William Chadwick and an anonymous referee. Research was supported by NASA grant NAGW 529 from the Planetary Geology and Geophysics Program, National Science Foundation grant EAR 9018216, and a visiting fellowslip from the Australian National University.

\section{REFERENCES}

Ballard, R.D., and J.G. Moore, Photographic Atlas of the Mid-Atlantic Ridge Rift Valley, 114 p., Springer-Verlag, New York, 1977.

Ballard, R.D., R.T. Holcomb, and Tj.H. van Andel, The Galapagos Rift at $86^{\circ} \mathrm{W}, 3$, Sheet flows, collapse pits, and lava lakes of the rift valley, J. Geophys. Res., 84, 5407-5422, 1979.

Ballard, R.D., J. Francheteau, T. Juteau, C. Rangan, and W. Normark, East Pacific Rise at $21^{\circ} \mathrm{N}$ : The volcanic, tectonic, and hydrothermal processes of the central axis, Earth Planet. Sci. Lett., 55, 1-10, 1981.

Baloga, S.M., and D. Pieri, Time-dependent profiles of lava flows. J. Geophys. Res., 91, 9543-9552, 1986.

Bischoff, J.L., and R.J. Rosenbauer, An empirical equation of state for hydrothermal seawater (3.2 percent $\mathrm{NaCl})$, Am. J. Sci., 285, 725-763 1985.

Blake, S., Viscoplastic models of lava domes, in Lava Flows and Domes. Emplacement Mechanisms and Hazard Implications, IAVCEI Proc. Volcanol., vol. 2, edited by J.H. Fink, pp. 88-128, Springer Verlag, New York, 1990.

Bonatti, E., and C.G.A. Harrison, Eruption styles of basalt in oceanic spreading ridges and seamounts: Effect of magma temperature and viscos. ity, J. Geophys. Res., 93, 2967-2980, 1988.

Borgia, A., S.R. Linneman, D. Spencer, L.D. Morales, and J.A. Brenes Dynamics of lava flow fronts, Arenal Volcano, Costa Rica, J. Volcanol. Geotherm. Res., 19, 303-329, 1983.

Carslaw, H.S., and J.C. Jaeger, Conduction of Heat in Solids, 2nd Ed.,510pp Oxford University Press, New York, 1959.

Chadwick, W.W., R.W. Embley, and C.G. Fox, Evidence for volcanic eruption on the southern Juan de Fuca Ridge between 1981 and 1987, Nature, 350, 416-418, 1991.

Crisp, J.A., and S.M. Baloga, A model for lava flows with two thermal components, J. Geophys. Res., 95, 1255-1270, 1990.

Delaney, P.T., and D.D. Pollard, Deformation of host rocks and flow of magma during growth of minette dikes and breccia-bearing intrusions near Ship Rock, New Mexico. U.S. Geol. Surv. Prof. Pap. 1202, 61 pp., 1981.

Dietrich, G., K. Kalle, W. Krauss, and G. Siedler, General Oceanography, 625 pp., John Wiley, New York, 1980.

Dowty, E., Crystal growth and nucleation theory and the numerical simulation of igneous crystallization, in Physics of Magmatic Processes, edited by R.B. Hargraves, pp. 419-485, Princeton University Press, Princeton, N.J., 1980.

Embley, R.W., K.M. Murphy, and C.G. Fox, High-resolution studies of the summit of Axial Volcano, J. Geophys. Res., 95, 12,785-12,812, 1990.

Embley, R.W., W.W. Chadwick, M.R. Perfit, and E.T. Baker, Geology of the northern Cleft segment, Juan de Fuca Ridge: Recent lava flows, sea-floor spreading, and the formation of megaplumes, Geology, 19,771-775, 1991.

Fink, J.H., and R.C. Fletcher, Ropy pahoehoe: Surface folding of a viscous fluid, J. Volcanol. Geotherm. Res., 4, 151-170, 1978.

Fink, J.H., and R.W. Griffiths, Radial spreading of viscous-gravity currents with solidifying crust, J. Fluid Mech., 221, 485-509, 1990.

Fink, J.H., and R.W. Griffiths, A laboratory analog study of the morphology of lava flows extruded from point and line sources, J. Volcanol. Geotherm. Res., in press, 1992.

Fofonoff, N.P., Physical properties of sea water, in The Sea, vol. 1, Physical Oceanography, edited by N.B. Hill, John Wiley, New York, 1962.

Griffiths, R.W., and J.H. Fink, The morphology of lava flows in planetary environments: Predictions from analog experiments, J. Geophys. Res, in press, 1992.

Gudmundsson, A., N. Oskarsson, K. Gronvold, K. Saemundsson, 0. Sigurdsson, R. Stefansson, S.R. Gislason, P. Einarsson, B. Brandsdottir, G. Larsen, H. Johannesson, and T. Thordarson, The 1991 eruption of Hekla, Iceland, Bull. Volcanol., 54, 238-246, 1992.

Hall, A., Igneous Petrology, 573 pp., Longman Scientific and Technical, Harlow, England, 1987.

Haymon, R.M., and the ADVENTURE Team, Active eruption seen on Eas Pacific Rise, Eos, Trans. AGU, 72 (46), 505-507, 1991.

Holcomb, R.T., J.G. Moore, P.W. Lipman, and R.H. Belderson, Voluminow 
submarine lava flows from Hawaiian volcanoes, Geology, 16, 400-404, 1988.

Hulme, G., The interpretation of lava flow morphology, Geophys. J. R. Astron. Soc., 39, 361-383, 1974

Huppert, H.E., and R.S.J. Sparks, Melting the roof of a chamber containing a hot turbulently convecting fluid, J. Fluid Mech., 188, 107-131, 1988.

Huppert, H.E., J.B. Shepherd, H. Sigurdsson, and R.S.J. Sparks, On lava dome growth, with application to the 1979 lava extrusion of the Soufriere of St Vincent, J. Volcanol. Geotherm. Res., 14, 199-222, 1982.

Kirkpatrick, R.J., Kinetics of crystallization of igneous rock, Rev. Mineral. 8, 321-398, 1981

Lipman, P.W., and N.G. Banks, Aa flow dynamics, Mauna Loa 1984, in Volcanism in Hawaii, edited by R.W. Decker, T.L. Wright, and P.H. Stauffer, pp. 1527-1567, U.S. Geol. Surv. Prof. Pap. 1350, 1987.

Lonsdale, P., Structural geomorphology of a fast-spreading rise crest, the East Pacific Rise near 3²5'S, Mar. Geophys. Res. 3, 251-293, 1977a.

Lonsdale, P., Abyssal pahoehoe with lava coils at the Galapagos rift, Geology, $5,147-152,1977 b$

Macdonald, G.A., Volcanoes, 510 pp., Prentice-Hall, Englewood Cliffs, N.J., 1972.

Malin, M.C., Lengths of Hawaiian lava flows, Geology, 8, 306-308, 1980.

Moore, J.G., Mechanism of formation of pillow lava, Am. Sci., 63, 269-277, 1975.

Moore, J.G., and J.P. Lockwood, Spreading cracks on pillow lava, J. Geol. 86, 661-671, 1978

Pinkerton, H., Factors affecting the morphology of lava flows, Endeavour 11, 73-79, 1987.

Pinkerton, H., and R.J. Stevenson, Methods of determining the rheologica properties of lavas from their physico-chemical properties, J. Volcanol. Geotherm. Res., in press, 1992.

Rowland, S.K., and G.P.L. Walker, Pahoehoe and aa in Hawaii: Volumetric flow rate controls the lava structure, Bull. Volcanol., 52, 615-628, 1990.

Ryan, M.P., and C.G.Sammis, The glass transition in basalt, J. Geophys. Res. $86,9516-9539,1981$
Sansome, F., Pele meets the sea, 27 minute video, LavaVideo Productions, Honolulu, Hawaii, 1990.

Shaw, H.R., Rheology of basalt in the melting range, J. Petrol., 10, 510-535, 1969.

Sverdrup, H.U., Oceanography for Meteorologists, 246 pp., Allen and Unwin, London, 1945.

Tepley, L., and J.G. Moore, Fire Under the Sea: The Origin of Pillow Lava, $16 \mathrm{~mm}$ sound motion picture, Moonlight Productions, Mountain View, Calif., 1974.

Turcotte, D.L., and G. Schubert, Geodynamics, 450 pp., John Wiley, New York, 1982.

Turner, J.S., Buoyancy Effects in Fluids, 368 pp., Cambridge University Press, New York, 1973.

Uhlmann, D.R., P.I.K. Onorato, and G.W. Scherer, A simplified model for glass formation, Proc. Lunar Planet. Sci Conf., 10th, 375-381, 1979.

van Andel, Tj.H., and R.D. Ballard, The Galapagos Rift at $86^{\circ} \mathrm{W}, 2$, Volcanism, structure, and evolution of the rift valley, J. Geophys. Res., 84, 53905406, 1979.

Walker, G.P.L., Lengths of lava flows, Philos. Trans. R. Soc. London, Ser. A, 274, 107-118, 1973.

Weast, R.C., D.R. Lide, M.J. Astle, and W.H. Beyer (Eds.), Handbook of Chemistry and Physics, 70th ed., CRC Press, Boca Raton, Fla., 1989.

Williams, H., and A.R. McBirney, Volcanology, 397 pp., Freeman, Cooper, San Francisco, Calif., 1979.

J.H. Fink, Geology Department, Arizona State University, Tempe, AZ 85287-1404.

R.W. Griffiths, Research School of Earth Sciences, Australian National University, GPO Box 4, Canberra ACT 2601, Australia.

(Received March 2, 1992; revised June 29, 1992; accepted July 8,1992 . 